\title{
Zum Gedenken an Professor Dr. Gerhard Taddey
}

\author{
Ansprache von Dr. ERnst Breit, Vorsitzender des Historischen Vereins \\ für Württembergisch Franken, bei der Trauerfeier im Ordenssaal des \\ Ludwigsburger Schlosses
}

Sehr geehrte Angehörige, sehr geehrte Trauergemeinde, als Professor Dr. Gerhard Taddey 1971 seine Arbeit im Hohenlohe-Zentralarchiv in Neuenstein aufnahm, trat er sogleich dem Historischen Verein für Württembergisch Franken bei. Von Beginn an wirkte er aktiv mit. Über mehr als 40 Jahre hinweg prägte er maßgeblich die Arbeit des Vereins. Er blieb ihm und der Region auch nach seinem Wechsel nach Stuttgart beziehungsweise Ludwigsburg eng verbunden.

Professor Taddey war bis zuletzt in der Schriftleitung des Jahrbuches „Württembergisch Franken" tätig. Für den Tag seines Todes, den 13. November 2013, hatten wir noch eine Besprechung mit ihm vereinbart, in der wir die Inhalte und Erscheinungstermine für die nächsten beiden Bände festlegen wollten. Doch es sollte nicht mehr dazu kommen. Zu der schweren Erkrankung kam noch eine Lungenentzündung, die der geschwächte Körper nicht mehr überstand. Schon bei dieser Besprechung ohne ihn merkten wir, wie sehr er uns als Ratgeber fehlen wird.

Wenn entschieden werden sollte, ob ein Beitrag in der Zeitschrift erscheinen solle oder nicht, so war sein fachliches Urteil - wie selbstverständlich - immer ausschlaggebend. Er zog aber nicht nur die Fäden im Hintergrund, er redigierte penibel und scheute sich auch nicht, ein Register zu erstellen.

Ähnliches galt für die Forschungsreihe von Württembergisch Franken, deren Mitherausgeber er über viele Jahre war. Die Vorsitzenden des Vereins trauten uneingeschränkt seinem Urteil. Klar, eindeutig und auch für den Nicht-Historiker nachvollziehbar waren seine Statements. Die hohe Qualität der Forschungsreihe verdankt der Verein nicht zuletzt dem Engagement und der Urteilskraft von Professor Taddey.

Seit 1989 richtet der Historische Verein in unregelmäßigen Abständen wissenschaftliche Tagungen zu regionalgeschichtlichen Themen im Bildungshaus Kloster Schöntal aus. Fast immer war Professor Taddey an der Planung beteiligt. Besonders bei den vorbereitenden Gesprächen waren wir jedes Mal vom umfassenden landesgeschichtlichen Wissen Professor Taddeys beeindruckt. Auf Grund seiner Kenntnisse und persönlichen Beziehungen waren schnell kompetente Fachleute für die Vorträge gewonnen und dank seiner Erfahrung und seines klaren Verstands waren die Tagungen bestens strukturiert. Oft übernahm er die wis- 
senschaftliche Leitung. Dann war garantiert, dass die Tagung den höchsten wissenschaftlichen Ansprüchen gerecht wurde, aber dass sie auch für Laien von Interesse war. Überhaupt war Professor Taddey die Vermittlung von historischen Erkenntnissen an ein breites Publikum ein Anliegen. Er scheute sich nicht, auch kleinere Beiträge für eher populäre Zwecke, etwa einen Bildband oder einen Kurzführer, zu verfassen, und er hat mehrfach zu Ausstellungen einführende Worte gesprochen oder Vorträge gehalten, die auch für Zuhörer ohne umfangreiche historische Vorkenntnisse einen Gewinn brachten. Er bereitete sie mit der gleichen Sorgfalt und Ernsthaftigkeit vor wie seine streng wissenschaftlichen Arbeiten.

Durch Herrn Professor Schindling wurde aus berufenem Munde das wissenschaftliche Werk von Professor Taddey gewürdigt. Ohne seine zahlreichen Schriften zu unserer Region aufzuführen, möchte ich doch hervorheben, dass ein Schwerpunkt seiner Forschungen in Württembergisch Franken lag. Er war ein exzellenter Kenner der Geschichte Hohenlohes ohne auf einen bestimmten Zeitraum spezialisiert zu sein. Man könnte auch sagen, er war mit ganzem Herzen Hohenloher. Sein Spektrum war enorm breit. Auf Grund seines schier unerschöpflichen Wissens und seiner methodischen Offenheit konnte er auch hervorragend fächerübergreifend arbeiten. Er publizierte unter anderem zur Baugeschichte etwa des Jagdschlosses Hermersberg oder schrieb über die Restaurierungen von Schloss Neuenstein. Und in seinem Beitrag „,Grabmäler der Hohenlohe“ zu einer Schöntaler Tagung stellte er neue Erkenntnisse zu kunsthistorisch wichtigen Bildhauerarbeiten vor, um nur einige Beispiele zu nennen.

Als Vertreter des Historischen Vereins darf ich auch sagen, dass wir stolz waren, als Professor Taddey mit seiner Arbeit „Kein kleines Jerusalem - Geschichte der Juden im Landkreis Schwäbisch Hall“" habilitiert wurde, mit einem Standardwerk, das in unserer Schriftenreihe erschienen war.

Dass Professor Taddey zu seinem 70. Geburtstag Ehrenmitglied des Vereins wurde, war nur selbstverständlich.

Wir sind Professor Taddey für seine Tätigkeit als Schriftleiter, also für die von ihm betreuten und selbstverständlich auch von ihm verfassten Publikationen, zu tiefem Dank verpflichtet. Vor allem aber wird er uns als Mensch fehlen. In den über 40 Jahren seines Wirkens in unserer und für unsere Region baten ihn vier Vorsitzende des Historischen Vereins immer wieder um Rat und um Unterstützung. Nicht einmal versagte er uns den Beistand. Mit seinem klaren, unbestechlichen Verstand und seinem von tiefer Menschlichkeit geprägten Handeln wird er uns stets in bester Erinnerung bleiben. 